\title{
Epistemic Ignorance, Poverty and the COVID-19 Pandemic
}

\section{Cristian Timmermann ${ }^{1}$ (D)}

Received: 5 June 2020 / Revised: 17 July 2020 / Accepted: 22 July 2020 / Published online: 30 July 2020

(C) National University of Singapore and Springer Nature Singapore Pte Ltd. 2020

\begin{abstract}
In various responses to the COVID-19 pandemic, we can observe insufficient sensitivity towards the needs and circumstances of poorer citizens. Particularly in a context of high inequality, policy makers need to engage with the wider public in debates and consultations to gain better insights in the realities of the worst-off within their jurisdiction. When consultations involve members of traditionally underrepresented groups, these are not only more inclusive, which is in itself an ethical aim, but pool ideas and observations from a much more diverse array of inhabitants. Inclusivity increases the odds to identify a larger range of weak spots for health security and to design health interventions that are less burdensome on those worst-off.
\end{abstract}

Keywords Public consultations · Pandemic $\cdot$ Poverty-sensitive $\cdot$ Cognitive diversity · Epistemic justice

\section{Introduction}

\section{Poverty and Public Health Interventions}

The insufficient experience with catastrophic disease outbreaks excuses many of the mistakes that have been made by policy makers during the COVID-19 pandemic. Plenty of uncertainties remain, as diagnosis has not been scaled up fast enough to deliver the needed data and the factors that increase vulnerability to the disease are still being unraveled. Yet, not all errors can be blamed on the uncertainties related to the particularities of the virus and its propagation. We can observe in a number of cases that policy makers were unaware of even the most basic circumstances under which large groups of people within their jurisdiction live and work. We may wonder, for instance,

Cristian Timmermann

cristian.timmermann@gmail.com

1 Centro Interdisciplinario de Estudios en Bioética, Universidad de Chile, Santiago, Chile 
why in the United States the professionals involved in recommending the use of masks - even when they are homemade - did not consider the effect this could have on African American males in a country with a scandalous record of racially biased police shootings against this particular group of citizens (Alfonso 2020)? The country has the means to efficiently upscale production and distribution of professional masks that could have reduced fears of having nothing else to wear than a homemade mask and would make it less easy for police officers with racial prejudices to misuse their power. In the Chilean capital, public authorities issued a night curfew without considering the effect this would have in making public transportation available on early hours, leading on the first days to massive agglomerations of commuters waiting in front of the subway stations until they opened to go to work. How could policy makers miss such a vital issue as ensuring that public transportation continues to work efficiently and safely in a city with 2.5 million daily subway passengers (Sepúlveda 2020)? In India, the government imposed on short notice a nationwide curfew demanding that people stay at home. This measure led to a massive exodus of migrant workers who had to walk from the major cities to their home villages, often for days, risking to spread the disease from cities to villages with little or no medical facilities (Roy 2020). Again here, one would expect a better knowledge among policy makers and their advisors of the circumstances of millions of their own population. Similar types of mistakes are still being made in the later stages of the pandemic, as politicians continue to be surprised to hear that large population groups are suffering from hunger and are breaking social distancing mandates in search for ways to gather income to meet their basic needs (Ehringfeld 2020). The negative effects of such policy failures become even stronger when politicians try to make up for the damage with populist strategies that contradict evidence-based recommendations from the social and health sciences. For instance, the Chilean government preferred to supply food boxes with media coverage to the poorest population segments instead of offering cash, despite the evidence from development studies indicating that such practices distort local markets, violate people's privacy and are vulnerable to high-level corruption. Such decisions show that policy makers are not only unaware of the circumstances of large population groups, but are even unconscious of the fact that they are missing the bigger picture, with the result that they do not seek, nor are open to consider different strategies suggested by people who have epistemic authority over the subject matter.

The repeated mistakes made while responding to the pandemic urge us to demand from policy makers to reevaluate how decisions are made. I proceed by offering a short explanation of the possible causes of the failure to foresee how decisions will negatively affect the poorest population segments. After that, I discuss the need for tailored programs that are sensitive to the needs of the different vulnerable groups. I conclude by arguing for inclusive public consultations and outline the main issues that need to be resolved to facilitate a poverty-sensitive dialogue.

\section{Closing Epistemic Gaps: Designing and Implementing Poverty-Sensitive Policies}

During the last weeks and months, we have witnessed a phenomenon common in early overseas development efforts: a naïve assumption that others have similar means and are subject to the same vulnerabilities. The inability to position oneself in the place of millions of people - a form of epistemic ignorance - makes us wonder about its cause. A common 
explanation for this type of ignorance is the lack of inclusion of people who have epistemic authority and first-hand knowledge on the subject matter. This is an issue that is commonly brought up by scholars from feminist and decolonization studies (Dübgen 2012). In some cases, these mistakes are a product of well-meant intentions; the firm commitment to treat everyone as equals may hinder people to recognize vulnerabilities and privileges even in cases where they ought to. Here, professional training that includes the study of narrative inquiries can increase awareness of one's own epistemic gaps and the need to seek advice from directly affected individuals. In other cases, a privileged social position can only be enjoyed while making a subconscious or even conscious effort to minimize or ignore the hardship faced by others. This inclination has been identified as aporophobia, as an aversion towards the poor, which leads the better-off to isolate from the needy and is particularly strong when poor people are subject to multiple forms of discriminations, such as racism and xenophobia (Cortina 2017). Here, we face a much more difficult problem, as dispositions in each one of us to prioritize our own well-being and to greed require awareness of the effect such inclinations have on others and a much stronger commitment to work towards our own ethical education.

While acknowledging the important role and successes of health scientists in insisting on evidence-based policy, there seems to be a major epistemic gap when it comes to systematically identify and foresee the effect new policies will have on the poor, minorities, persons with disabilities and migrants, and the added vulnerabilities triggered by racism and violence against particularly women. Evidence suggesting that a public health intervention works well for one particular group does not imply that from a socioeconomic perspective, it will lead to the same results when applied to other sectors (Moodley et al. 2020). One-size-fits-all policy approaches can lead to enormous harm if they ignore the multiple effects of massive inequalities within and between countries, demographic differences and the capacity of public health infrastructure (Broadbent and Smart 2020). In the Global South, measures against COVID-19 are having a negative effect on vaccination rates, malnutrition and women surviving labor (Broadbent et al. 2020). Moreover, many state officials in power are biased towards downplaying the extensiveness of poverty as it would reveal political failure. As a consequence, they fail to acknowledge the need to adapt health policies from wealthy countries to the local circumstances to not openly recognize the existence of extreme poverty and the precariousness of public infrastructure. This pandemic is not a unique case calling for sensitivity to the local circumstances when implementing policies of global reach. Perhaps the most documented example of how standardized policies may have disastrous effects on global health is the access to medicine crisis after the Agreement on Trade-Related Aspects of Intellectual Property Rights (1995) led to a sharp increase in prices for antiretrovirals by making it more difficult to export generics (Kapczynski 2019). COVID-19 has made it clear again that evidence-based policy should not be grounded in up-to-date knowledge from the health sciences alone, but needs to fully acknowledge findings from the social sciences and encourage more interdisciplinary work between the health and social sciences.

Scientists themselves should also be aware of their biases and disciplinary limitations. This is particularly important when providing policy advice. For instance, the very term "evidence-based policy" may imply an uncontested precision that simply cannot be claimed under the high uncertainty of COVID-19 (Saltelli et al. 2020). To maintain public trust in science, the early experience during the pandemic suggests that 
scientists should also be much more careful on how they communicate their findings and predictions. The messages scientists deliver to state officials and disclose to the public are likely to affect people's conduct and expectations (Halpern et al. 2020). Making sensational claims may deteriorate overall trust in science when the public sees that the promises are not being fulfilled (Provenzi and Barello 2020). At the same time, modelers need to be careful not to give the impression that their calculations are precise and be open about the normative values of their choices and the unknown factors (Saltelli et al. 2020). To avoid that scientific findings and models are used out of context by opportunistic politicians, or that eager scientists make exaggerated claims public to advance their career, scientists of the different disciplines need to work together to improve the way new scientific observations are being communicated and to encourage outsiders to voice objections and amendments to their recommendations.

An important tool from the social sciences and humanities to recognize the differential impact of public health interventions on vulnerable groups is the capability approach. Central to this approach is the claim that people are entitled to be and do what they value as a part of a decent life. This approach allows us to identify from the point of view of specific groups the impact new health measures have on pursuing the things people value to be and do (Venkatapuram 2020). Another example is the interdisciplinary collaboration between epidemiologists and behavioral scientists, which offers several suggestions on how to improve public communication and addresses biases leaning towards excessive optimism and favoring the improvement of treatment capacities against the implementation of preventive public health measures (Halpern et al. 2020).

Policy makers should therefore embrace some intellectual humility and acknowledge that there are limitations in the amount of information and perspectives each one of us can effectively assess. There are certain issues people in privileged or relatively more advantaged positions fail to recognize or sometimes even forget. Particularly in the context of extreme inequality of income, education level and social vulnerability, as we face both within and between countries, and the enormous advantage financial resources give to become democratically elected, it does not come as a surprise that ruling groups that are largely alienated from the realities of the general population are overrepresented among political authorities.

To avoid these epistemic gaps, that is the inability to anticipate how certain policies will affect vulnerable groups, we need to ensure the participation of people of all walks of life to facilitate a sufficient range of perspectives (i.e., cognitive diversity) among decision makers that adequately reflects the population and the different circumstances people encounter (Kitcher 2011). We need to realize that to maintain cognitive diversity, quotas for underrepresented groups on themselves may not be representative enough, as they are likely to be filled by the most talented, hard-working and often childless people competing for these jobs, who may also end up disconnected from the needs, capacities and circumstances of their former peers. To fill a percentage of the positions through a form of lottery has also limitations, as those selected may not have the necessary qualifications, training and enthusiasm to assess health policies and their implications. An alternative approach to examine whether the policies have negative effects on the different population segments is to build inclusive decision-making processes that actively seek input from the wider population through public consultations. 
There are several factors that call for broader public involvement during the COVID-19 pandemic. First, initial studies on the dangers of the virus overestimated the fatality rate and later studies underestimated its lethality (Smriti 2020), eroding trust among the public regarding the reliability of scientific advice. Second, from early on, the public learned that older people are at much higher risk of developing complications, creating a false sense of safety and some divisions among the population (Gosseries 2020). Third, investigations showed relatively early that in several countries, poorer minorities are much likelier to die from the virus due to higher work-related exposure and differential access to medical treatment (Gostin et al. 2020). All these factors disintegrate social cohesion, making it necessary to bring the different affected groups together so that they can voice their concerns and be listened to.

While the idea of public consultation is old, we need to keep in mind that developments in technology and research on continuous education allow us nowadays to be much better prepared for public outreach. We can provide up-to-date information to a much larger percentage of the population with the help of communication technologies, and science educators are now better equipped to pass on key knowledge to the public by using sophisticated graphics, diagrams showing the development of current events and take advantage of the enormous experience gathered over the last decades in improving the public understanding of science. Governments can reach poorer population groups by working with telecommunication companies to liberate mobile data to facilitate access to public health information and by making effective use of broadcasting channels. Important is also that there is an increasing recognition that the general public can provide crucial feedback and possess a vital pool of knowledge, particularly when it comes to assess social policies (Reiss 2019). The enormous rise in the number of citizen science projects and open innovation initiatives are strong examples of the success of public outreach initiatives (Wiggins and Wilbanks 2019; Fiske et al. 2019). Here, it is crucial to recognize the huge potential people who grew up and live under very different conditions have in identifying problematic issues and suggest more effective strategies. Nowadays, we also need to acknowledge that developments in technology and science education may also increase the expectation among the public on when they should be consulted. As these developments facilitate and speed up public outreach processes, governments cannot as readily excuse their shortcomings in inclusive decision-making and transparency by pointing to time constraints. The harsh impact of public health interventions on low income-earners - particularly in countries that reacted late to the COVID-19 pandemic - reveals that policies were often not even consulted with a small group of underprivileged citizens. Nonetheless, it is recommendable that a series of public consultations are made in advance to find out how citizens will react in view of possible scenarios, so that their input can be used to build templates to guide ethical decision-making during future emergencies (Smith and Upshur 2019). In the present case, it is unclear in how far countries who prepared for a pandemic really relied on earlier simulations. Outside East Asia and parts of Africa, the vast majority of countries have shown insufficient pandemic preparedness, some even with disastrous results.

To make public consultations effective, work will need to be done to ensure that underrepresented people are able to express their voice and that the participants are willing to engage with other points of view and forms of expressions. An active effort will need to be done to confront epistemic injustices that either discriminate against 
certain groups of participants or the ways some members of the public express themselves (Fricker 2007). The use of slang or the failure to master a country's official or dominant language should not have the effect that other participants belittle its epistemic content. As the pandemic is likely to increase anxiety and anguish among the most affected people, it is also crucial that participants in a dialogue retain the capacity to critically assess without biases the central message someone is expressing in the middle of panic, rage or even while crying (cf. Bayruns Garcia 2019). Ethical decisionmaking requires the inclusion of diverse voices and condemns practices that make it easier to ignore specific groups. Ignoring the input of such groups is a case of testimonial injustice, as they are not given a fair opportunity to contribute to a dialogue due to their group membership. Furthermore, ethical decision-making needs to acknowledge that specific groups are in a distinct position that needs to be treated separately to respond to their specific vulnerabilities; otherwise, they face a situation of hermeneutical injustice where the peculiarities of their circumstances are ignored or misrepresented in systematic assessments (cf. Fricker 2007; Ahmad et al. 2020). For instance, public consultations should not ignore the fact that many undocumented immigrants live among us and that efficient health policies need to identify their particular needs and vulnerabilities. Ignoring their voices exposes them and the rest of the population to COVID-19, as the experience of Singapore made clear to other countries (Segrave 2020). One can only stimulate the participation of undocumented migrants when they are given immunity when providing critical feedback to public consultations and do not have to fear from standing out reprisals against other migrants or themselves. A dialogue that is truly inclusive must accommodate the different forms of expression and should actively encourage people to contribute to solving a public problem by sharing their insights and ideas (Timmermann 2018). An efficient cooperative society is characterized by its ability to pool knowledge and information from diverse sources and therefore needs to guarantee freedom and build capacities so all can share freely valuable information (Harari 2020). Inclusiveness in decision-making also leads to higher decision ownership, which increases compliance with commonly agreed public health measures (Gopichandran et al. 2020).

An inclusive dialogue on its own will, however, not lead to efficient health policies. To benefit from diverse inputs, it is essential to appoint good arbiters that chair sessions and make sure voices from all affected groups have an opportunity to express themselves and that the discussion is not dominated by a few persons. Participants in public consultations should not experience in the debate the same unfair advantages or unwelcomed use of power, when it comes to speaking and being listened to, that they face in their everyday lives. To achieve participatory parity, also more subtle ways of dominating discourses need to be confronted, such as twisting meanings, decontextualizing statements and affirming that one is merely disclosing what the silent mass is thinking despite having no such evidence or while blatantly lying to put one's own interests on the agenda (Fraser 1990). Such sessions should also count with people who have the ability to synthesize in a respectful and accurate manner the different viewpoints and suggest priorities that can be commonly agreed upon. The importance of establishing harmony and finding common ground cannot be understated in the current pandemic (LolasStepke 2020), especially in view of the enormous inequalities in terms of disease vulnerability and quarantine hardship. 
A good chair in discussions should also make participants aware that expanding the number of participants is only one of the main procedural values needed to establish a discourse seeking to improve the ethical acceptability and poverty sensitivity of public health interventions. Besides being inclusive, decision-making needs to be reasonable, open and transparent, responsive and accountable (Upshur et al. 2005). While multiscale approaches that seek to alleviate the hardship of quarantine and social distancing measures are welcomed and even necessary, prioritizations and exemptions to rules need to be well-justified and commonly agreeable, which requires excellent public communication skills to reach all affected inhabitants. Citizens need to know why their freedoms are being curtailed and they need to be provided a good justification of why some groups of people are being exempted. In terms of openness and transparency, the non-participating public still needs to be able to access without facing hurdles the information, data and arguments that support decisions. As far as responsiveness concerns, it is essential that previously supported measures can be questioned and revised as new evidence emerges and that developments are continuously monitored. Lastly, in terms of accountability, participants in public consultations need to understand that they should not draw their decisions lightly, as public health policies may have strong effects on freedoms and entitlements that are protected by national constitutions and human right declarations and that they may be accountable for gross neglects or violations of rights. This last point should not be seen as a mere formality in times where populist agendas, xenophobia and racism are on the rise. Any intervention that limits the rights of people needs to adhere to principles of proportionality, strictly demanding justification and countermeasures to alleviate any negative effects (idem).

\section{Concluding Remarks}

Eventual difficulties in reaching and including certain groups should not be taken as an excuse to immediately terminate efforts. One cannot expect that members of groups who have been historically discriminated against will be immediately interested in cooperating. Distrust in the good intentions of governments is abundant (Baum et al. 2009; Gopichandran et al. 2020). Many groups have a long-time mistrust when it comes to relying on their governments to watch over their safety and well-being. The enormous differences in how the virus is affecting racial and ethnic minorities, as we see among the black and Latino population in the United States (Fairchild et al. 2020; Elbaum 2020), or citizens with black, Asian or other minority ethnic background in the United Kingdom (Siddique 2020), show that their mistrust is not misplaced. It will take work to regain certain citizen groups as cooperation partners due to historical injustices. At the same time, we need to fully acknowledge existing biases and privileges that make it much easier to ignore one part of the population and not the other. Public consultations have two central aims: to seek information and to bring people together. Not only human decency obliges us to make up for the historic failure to reach out to underrepresented groups and fight discrimination that allows to ignore certain voices, health security obliges us to address these policy gaps by making sure everyone is willing and able to cooperate with public health measures (Ruger 2020; Gostin et al. 2020). To not consider the circumstances of large population groups and unnecessarily expose them to infectious diseases is not only unjust, it is bad health politics. 
Acknowledgements I wish to thank the journal's editor, Graeme Laurie, and an anonymous reviewer for helpful comments.

Authors' Contributions I am the sole author.

\section{Compliance with Ethical Standards}

Conflict of Interest The authors declare that they have no conflict of interest.

\section{References}

Ahmad, Ayesha, Ryoa Chung, Lisa Eckenwiler, Agomani Mitra Ganguli, Matthew Hunt, Rebecca Richards, Yashar Saghai, Lisa Schwartz, Jackie Leach Scully, and Verina Wild. 2020. What does it mean to be made vulnerable in the era of COVID-19? Lancet 395: 1481-1482. https://doi.org/10.1016/S0140-6736 (20)30979-X.

Alfonso, Fernando. 2020. Why some people of color say they won't wear homemade masks. CNN, 7 April 2020. https://edition.cnn.com/2020/04/07/us/face-masks-ethnicity-coronavirus-cdc-trnd/.

Baum, Nancy M., Peter D. Jacobson, and Susan D. Goold. 2009. "Listen to the people": public deliberation about social distancing measures in a pandemic. American Journal of Bioethics 9 (11): 4-14. https://doi. org/10.1080/15265160903197531.

Bayruns Garcia, Eric. 2019. Expression-style exclusion. Social Epistemology 33 (3): 245-261. https://doi. org/10.1080/02691728.2019.1621403.

Broadbent, Alex, and Benjamin T. H. Smart. 2020. Why a one-size-fits-all approach to COVID-19 could have lethal consequences. The Conversation, updated 24 March 2020. https://theconversation.com/why-a-onesize-fits-all-approach-to-covid-19-could-have-lethal-consequences-134252.

Broadbent, Alex, Damian Walker, Kalipso Chalkidou, Richard Sullivan, and Amanda Glassman. 2020. Lockdown is not egalitarian: the costs fall on the global poor. Lancet 396: 21-22. https://doi. org/10.1016/S0140-6736(20)31422-7.

Cortina, Adela. 2017. Aporofobia, el rechazo al pobre: un desafio para la democracia. Barcelona: Ediciones Paidós.

Dübgen, Franziska. 2012. Africa humiliated? Misrecognition in development aid. Res Publica 18: 65-77. https://doi.org/10.1007/s11158-012-9186-2

Ehringfeld, Klaus. 2020. Wie die Titanic vor dem Eisberg. Der Spiegel, 1 June 2020. https://www.spiegel. $\mathrm{de} /$ politik/ausland/chile-in-der-corona-krise-wie-die-titanic-vor-dem-eisberg-a-f5c2a3ed-1771-44a0-8edad5943dc2f50d.

Elbaum, Alan. 2020. Black lives in a pandemic: implications of systemic injustice for end-of-life care. Hastings Center Report 50 (3): 58-60. https://doi.org/10.1002/hast.1135.

Fairchild, Amy, Lawrence Gostin, and Ronald Bayer. 2020. vexing, veiled, and inequitable: Social distancing and the "rights" divide in the age of COVID-19. American Journal of Bioethics 20 (7): 55-61. https://doi. org/10.1080/15265161.2020.1764142.

Fiske, Amelia, Lorenzo Del Savio, Barbara Prainsack, and Alena Buyx. 2019. Conceptual and ethical considerations for citizen science in biomedicine. In Personal health science, ed. Nils B. Heyen, Sascha Dickel, and Anne Brüninghaus, 195-217. Wiesbaden: Springer.

Fraser, Nancy. 1990. Rethinking the public sphere: a contribution to the critique of actually existing democracy. Social Text 25/26: 56-80. https://doi.org/10.2307/466240.

Fricker, Miranda. 2007. Epistemic injustice: power and the ethics of knowing. Oxford: Oxford University Press.

Gopichandran, Vijayaprasad, Sudharshini Subramaniam, and Maria Jusler Kalsingh. 2020. COVID-19 pandemic: a litmus test of trust in the health system. Asian Bioethics Review 12: 213-221. https://doi. org/10.1007/s41649-020-00122-6.

Gosseries, Axel. 2020. Trois questions éthiques sur la place des plus âgés dans la pandémie. The Conversation, 18 May 2020. https://theconversation.com/trois-questions-ethiques-sur-la-place-des-plusages-dans-la-pandemie-133822. 
Gostin, Lawrence O., Eric A. Friedman, and Sarah A. Wetter. 2020. Responding to COVID-19: how to navigate a public health emergency legally and ethically. Hastings Center Report 50 (2): 8-12. https://doi. org/10.1002/hast. 1090

Halpern, Scott D., Robert D. Truog, and Franklin G. Miller. 2020. Cognitive bias and public health policy during the COVID-19 pandemic. JAMA, published online 29 June 2020. https://doi.org/10.1001 /jama.2020.11623.

Harari, Yuval Noah. 2020. In the battle against coronavirus, humanity lacks leadership. Time, 15 March 2020. https:/time.com/5803225/yuval-noah-harari-coronavirus-humanity-leadership/.

Kapczynski, Amy. 2019. The right to medicines in an age of neoliberalism. Humanity 10 (1): $79-107$. https://doi.org/10.1353/hum.2019.0003

Kitcher, Philip. 2011. Science in a democratic society. Amherst: Prometheus Books.

Lolas-Stepke, Fernando. 2020. Perspectivas bioéticas en un mundo en sindemia. Acta Bioethica 26 (1): 7-8. https://doi.org/10.4067/S1726-569X2020000100007.

Moodley, Keymanthri, Laurent Ravez, Adetayo Emmanuel Obasa, Alwyn Mwinga, Walter Jaoko, Darius Makindu, Frieda Behets, and Stuart Rennie. 2020. What could "fair allocation" during the Covid-19 crisis possibly mean in sub-Saharan Africa? Hastings Center Report 50 (3): 33-35. https://doi.org/10.1002 hast.1129.

Provenzi, Livio, and Serena Barello. 2020. The science of the future: establishing a citizen-scientist collaborative agenda after Covid-19. Frontiers in Public Health 8: 282. https://doi.org/10.3389 /fpubh.2020.00282.

Reiss, Julian. 2019. Expertise, agreement, and the nature of social scientific facts or: against epistocracy. Social Epistemology 33 (2): 183-192. https://doi.org/10.1080/02691728.2019.1577513.

Roy, Arundhati. 2020. The pandemic is a portal. Financial Times, 3 April 2020. https://www.ft. com/content/10d8f5e8-74eb-11ea-95fe-fcd274e920ca.

Ruger, Jennifer Prah. 2020. Positive public health ethics: towards flourishing and resilient communities and individuals. American Journal of Bioethics 20 (7): 44-54. https://doi.org/10.1080 /15265161.2020.1764145.

Saltelli, Andrea, Gabriele Bammer, Isabelle Bruno, Erica Charters, Monica Di Fiore, Emmanuel Didier, Wendy Nelson Espeland, John Kay, Samuele Lo Piano, and Deborah Mayo. 2020. Five ways to ensure that models serve society: a manifesto. Nature 582: 482-484. https://doi.org/10.1038/d41586-020-018129.

Segrave, Marie. 2020. The coronavirus risk Australia is not talking about: testing our unlawful migrant workers. The Conversation, 6 May 2020. https://theconversation.com/the-coronavirus-risk-australia-isnot-talking-about-testing-our-unlawful-migrant-workers-137268.

Sepúlveda, Nicolás. 2020. Crece el brote de Covid-19 en el Metro: siete trabajadores dieron positivo y 87 están en cuarentena. CIPER, 24 March 2020. https:/ciperchile.cl/2020/03/24/crece-el-brote-de-covid-19en-el-metro-siete-trabajadores-dieron-positivo-y-87-estan-en-cuarentena/.

Siddique, Haroon. 2020. equality watchdog urged to investigate coronavirus impact on BAME people. The Guardian, 10 May 2020. https://www.theguardian.com/world/2020/may/10/equality-watchdog-urgedinvestigate-impact-on-bame-people-london-mayor.

Smith, Maxwell J., and Ross Upshur. 2019. Pandemic disease, public health, and ethics. In Oxford Handbook of Public Health Ethics, ed. Anna C. Mastroianni, Jeffrey P. Kahn, and Nancy E. Kass, 797-811. New York: Oxford University Press.

Smriti, Mallapaty. 2020. How deadly is the coronavirus? Scientists are close to an answer. Nature 582: 467468. https://doi.org/10.1038/d41586-020-01738-2.

Timmermann, Cristian. 2018. Contributive justice: an exploration of a wider provision of meaningful work. Social Justice Research 31 (1): 85-111. https://doi.org/10.1007/s11211-017-0293-2.

Upshur, Ross, Karen Faith, Jennifer L. Gibson, Alison K. Thompson, C. Shawn Tracy, Kumanan Wilson, and Peter A. Singer. 2005. Ethical considerations for preparedness planning for pandemic influenza. Toronto: University of Toronto Joint Centre for Bioethics Pandemic Influenza Working Group.

Venkatapuram, Sridhar. 2020. Human capabilities and pandemics. Journal of Human Development and Capabilities, published online 30 June 2020. https://doi.org/10.1080/19452829.2020.1786028.

Wiggins, Andrea, and John Wilbanks. 2019. The rise of citizen science in health and biomedical research. American Journal of Bioethics 19 (8): 3-14. https://doi.org/10.1080/15265161.2019.1619859.

Publisher's Note Springer Nature remains neutral with regard to jurisdictional claims in published maps and institutional affiliations. 